\title{
Los gitanos condenados como galeotes en la España de los Austrias
}

\author{
MARIA HELENA SÁNCHEZ ORTEGA \\ UNED, MADRID
}

\section{The Gipsies condemned to galleys in Hapsburg Spain}

\begin{abstract}
RESUMEN ABSTRACT
Los gitanos españoles sufrieron la pena de galeras, al igual que otros condenados por la Inquisición o la justicia civil. Ahora bien, a pesar de que las medidas que se adoptaron contra ellos fueron frecuentes, no son muchos los hombres condenados a este castigo y pocos los que que finalmente fueron a parar a galeras.

PALABRAS CLAVE: gitanos / galeotes / España / Edad Moderna

Spanish gypsies were condemned to the royal galleys as well as others prosecuted by Spanish Inquisition or by civil justice. However, though sentences were pronounced against them very often, not many were condemned, and very few suffered actually this penalty.

KEYWORDS:

gipsies / galley slaves / Spain / Early Modern Age

Al igual que otros muchos condenados por los tribunales civiles o inquisitoriales, los gitanos fueron a parar en algunas ocasiones a las galeras reales para cumplir penas de cuatro, seis, ocho o más años. Los vagabundos y ladrones —entre los que se incluía a los gitanos-, así como blasfemos, perjuros, rufianes, maridos «consentidores» y los que ocultaban a algún fugitivo a la justicia real, estaban destinados a cubrir estos trabajos forzados desde principios del siglo $\mathrm{XVI}^{1}$.
\end{abstract}

${ }^{1}$ Acerca de la implantación y evolución de la pena de galeras en España deben verse los trabajos desde el punto de vista jurídico de F. Solanas SeVILLA, Historia penitenciaria española (La galera), Segovia, Estudio Tipográfico de «El Adelantado de Segovia», 1917. También, el más reciente de R. PIKE, Penal servitude in Early Modern Spain, Madison University of Wisconsin Press, 1983. 
La pena de galeras estaba considerada como uno de los castigos más graves a que podía ser condenado cualquier hombre. Se trataba de una prueba tan difícil de superar que en la legislación de los siglos XVI, XVII y XVIII aparece como el grado superior al que podía ser destinado un reo, lo que condujo probablemente, entre otras razones, a que los legisladores castellanos la destinaran en un principio para conmutar las sentencias precisamente de aquellos hombres a quienes se había sentenciado a muerte. Aunque los fueros viejos de Aragón prohibían que se aplicara este tipo de castigo, excepto contando con el asentimiento del interesado², en Castilla se permitió, mediante una cédula del 2 de noviembre de $1502^{3}$, la conmutación de la pena de muerte por la de este castigo.

La actitud del rey Fernando contaba ya con el antecedente establecido en Castilla con motivo de la empresa de Colón. Aunque los miembros de las tripulaciones de los dos primeros viajes estuvieron compuestas por hombres libres y profesionales del mar, durante el tercer viaje ya había disminuido el entusiasmo y la curiosidad que provocaron los primeros descubrimientos, y el almirante se vio obligado a recurrir a cierto número de ex-presidiarios que se prestaron a la aventura a cambio de redimir las penas de carácter grave a que habían sido destinados. Es decir, se trataba de hombres y mujeres que debían sufrir la de muerte o pérdida de algún miembro, pero se exceptuaba a los que habían traficado con moneda falsa. Todo ello se dispuso mediante una real cédula, y entre ellos se encontraban dos parejas de gitanos, Macías y Antón de Egipto con sus respectivas mujeres (María y Catalina).

La legislación dirigida a reclutar esta mano de obra imprescindible para las necesidades bélicas del país empieza a comprender cada vez mayor número de delitos, según cabía esperar, a medida que van en aumento las contingencias que determinan su aparición. Esta situación se observa con mucha claridad a través de las sentencias dictadas por el tribunal de la Inquisición contra reos que se consideran merecedores de esta pena. La campaña italiana decide al rey Fernando a solicitar un Breve de Alejandro VI, concedido el 28 de mayo de 1503, para que el Santo Oficio pueda utilizar este castigo contra algunos condenados y, al igual que en Castilla, como un servicio que permitía sustituir la prisión perpetua o el destierro a las colonias. Como consecuencia de esta medida, 19 galeotes embarcaron en Barcelona en 1505 con destino a la conquista de Nápoles 5 .

\footnotetext{
${ }^{2}$ Henry Charles LEA hace un resumen de la implantación de la pena de galeras en el Santo Oficio en su monumental estudio A History of the Inquisition of Spain, reimpresión, Nueva York, Ams Press, 1966 (vol. III, cap. III, pp. 141 ss.).

3 Ibidem.

${ }^{4}$ La relación de estos acompañantes de Colón en su tercer viaje fue publicada por J. GIL: «El rol del tercer viaje colombino", en Historiografía y bibliografía americanistas, vol. XXIX (1985), pp. 83-110 (la referencia en p. 102). F. SEVILLA y SolANAS se refiere también a este episodio en los siguientes términos: «A Colón —-por no encontrar aventureros que le acompañaran en su atrevida empresa que consideraban obra de un vesánico- le acompañaron en sus primeras expediciones de descubrimiento algunos delincuentes a quienes se les indultó de las penas a que habían sido condenados, pero con la condición de efectuar estos viajes» (Historia..., p. 29).

${ }^{5}$ H. Ch. LEA, A History...
} 
Circunstancias similares conducen a Carlos I en 1529 y a Felipe II en 1558 a utilizar de nuevo los servicios de estos supuestos culpables. La legislación inquisitorial nos permite ver cómo se van incorporando a este trabajo los blasfemos, los bígamos y aquellos individuos que intentan suplantar las funciones del Santo Oficio o las de los sacerdotes diciendo misa sin estar ordenados, con penas que oscilan entre los tres y cuatro años de servicio6.

La situación es muy similar en el caso de la legislación civil. De acuerdo con la justicia real, los ladrones fueron condenados según la Pragmática de Don Carlos, Doña Juana y el príncipe Felipe a la pena de galeras a partir del año $1552^{7}$. La pragmática ordenaba sustituir el castigo de azotes a que se les condenaba anteriormente por cuatro años de galeras, en la primera condena, siempre que fueran mayores de veinte años. La segunda vez, recibirían cien azotes y servirían perpetuamente en ellas. Cuando el hurto se hubiera llevado a cabo en la Corte, las penas serían mayores, cien azotes y ocho años al remo la primera vez, y doscientos azotes y galera perpetua la segunda, siempre que superaran esta edad.

La misma severidad se muestra con los «vagamundos» a partir de estas fechas. Según la Pragmática de Don Carlos y Doña Juana, también del año 1552, los vagabundos quedaban destinados a las galeras, en lugar del anterior castigo de azotes, durante cuatro años después de la primera condena, cuando el reo tuviera más de veinte años. La segunda vez que se le encontrara culpable, se le destinaría al servicio de galeras, en lugar de la anterior pena de azotes, durante cuatro años, siempre que se cumpliera la misma condición de ser mayor de veinte años. En la tercera ocasión, recibiría cien azotes y sería condenado a ocho años de galeras. En la tercera ocasión pasaban a permanecer perpetuamente al servicio real.

Como vemos, la actitud de la Corona hacia los vagabundos era la misma que respecto a los gitanos, aunque los miembros de la minoría ya habían sido condenados a seis años al remo desde 1539, de acuerdo con la Pragmática de Carlos I y doña Juana, ratificada más tarde por Felipe II en $1560^{\circ}$. Por lo que se refiere a los miembros de la minoría, las pragmáticas evolucionan de acuerdo con las pautas siguientes, en caso de que se nieguen a aceptar la pena de destierro a que quedaron sujetos hasta el 15 de febrero de 1633:

1539-1560: 6 años de galeras.

1633

: 200 azotes y 6 años de galeras.

: en caso de que se les encuentre con armas de fuego, la pena aumenta a 8 años de galeras.

6 Ibidem

7 Nueva Recopilación de las leyes destos Reinos hecha por mandado de la Magestad Catholica del Rey don Felipe III, 1640. (edición facsímil, s. I., Lex, 1982).

8 Nueva Recopilación... 
$1695: 6$ años de galeras para aquel gitano que se niegue a ser registrado en el censo ordenado por Carlos II. Es posible, sin embargo, que este censo no se llevara nunca a cabo.

: 8 años de galeras para los que usen armas, vayan acuadrillados o sean encontrados con armas.

$1717: 6$ años de galeras y 100 de azotes.

: 8 años de galeras y 200 azotes para los que usen armas?

A medida que aumentan las necesidades bélicas del país, los tribunales civiles van ampliando también sus competencias respecto a los delitos que pueden conducir a un condenado al terrible castigo de las galeras. La actuación de estos tribunales parece a este respecto mucho más contundente que la del Santo Oficio. El reinado de Carlos I representa, durante el siglo XVI, el primer esfuerzo serio de la Corona para reclutar brazos con destino al servicio del mar, actitud que se incrementa con la subida al trono de Felipe II y las contingencias de su reinado. A partir de 1566 se condena a este mismo servicio a los rufianes, a los maridos que consintieran el adulterio de su esposa y a algunos reos procedentes de la jurisdicción inquisitorial. Los bígamos, blasfemos y perjuros pasan a recibir castigos similares, según hemos visto.

Según parece evidente, la situación de los gitanos empeora, al menos en teoría, de acuerdo siempre con las tendencias generales de los legisladores respecto a otros grupos similares. En las páginas que siguen podremos observar, sin embargo, que la dureza de las medidas que se pretendían adoptar contra estos grupos tropezaron en la práctica - afortunadamente para todos ellos - con una variada casuísitica que obliga a matizar la cruda impresión que produce la lectura de las disposiciones legales. Según las leyes dictadas a propósito de la conmutación de las penas corporales por la pena de galeras - que comienzan a emitirse también a partir del siglo XVI- todos los reos condenados a este tipo de castigos, sin hacer mención de etnia o grupo social, tales como cortarles una mano o pie, destierro perpetuo o alguna situación similar, pueden ver conmutado este castigo por el de galeras por tiempo discrecional siempre que no sea inferior al de dos años y siempre que no sea en perjuicio de la «parte querellosa». Así lo dispone Carlos I el 31 de enero de 1530, el 16 de mayo de 1534 y el 23 de febrero de 1535. Felipe II, en la pragmática de mayo de 1560, se pronuncia en el mismo sentido respecto a los robos y salteamientos cometidos en los caminos en el campo. Felipe II vuelve a ratificarse a este respecto en la pragmática de 3 de mayo de 1566. Para evitar que la «parte querellosa» pueda impedir la puesta en práctica de estas disposiciones, estipula que «aunque haya perdón de parte, siendo el delito y persona de calidad que justamente pueda ser condenado en pena corporal, sea y pueda ser

9 Estos datos aparecían ya en mi libro Los gitanos españoles. El periodo borbónico, Madrid, Castellote, 1977, donde también puede consultarse un capítulo acerca de la legislación contra los gitanos en España. Los textos completos de esta legislación pueden consultarse en mi libro Documentación selecta sobre la situación de los gitanos españoles en el siglo XVIII, Madrid, Editoria Nacional, 1977. 
puesta la dicha pena de servicio de galeras por el tiempo que según la calidad de la persona y del caso paresciere que se puede poner $>10$.

Felipe III endurece la disposición en la real cédula de 3 de septiembre de 1611:

«Mandamos que ningún galeote, que estuviere condenado y llevado a las cárceles de Toledo o Soria, o a las demás que se llevan, conforme a la orden que por leyes y cédulas está dada, sea oido en pretensión ninguna, que toque a su libertad, por ningun caso, como es intentar juicio de inmunidad de iglesia o de enfermedad que impida ir a servir, sino que sin embargo destos y qualesquier impedimentos sean luego llevados desde las dichas cárceles adonde el mismo Consejo de la Guerra hubiere ordenado, sin detener ninguna desde una cadena para otra»11.

Al igual que en el caso de las pragmáticas anteriores a propósito de los reos destinados directamente a las galeras, la situación de estos desgraciados es preciso analizarla a la luz de la variedad de circunstancias que parecen presentar a continuación los documentos, que proceden en ocasiones del propio Consejo y en otras de la práctica cotidiana de la justicia.

Según parece, las excepciones a estas medidas tan estrictas respecto a la conmutación de las penas corporales no fueron excepcionales. Los hombres destinados a este servicio no carecían, sin embargo, totalmente de recursos para apelar a la justicia y tratar, a través de este recurso legal, de conmutar el castigo o atenuarlo. Con alguna frecuencia, según veremos a continuación, los galeotes consiguieron la libertad mediante indultos o sustituir este destino por otro más benigno, pero, por lo general, las necesidades de la guerra obligaron a los monarcas a intentar con cierta frecuencia levas que les proporcionaran los presidiarios - «chusma» se dice en los documentos de la época-imprescindibles para sus objetivos.

En consecuencia con la legislación que acabamos de revisar, a lo largo de los siglos XVI y XVII aparecen con cierta frecuencia testimonios acerca de los condenados a este tremendo castigo, que muchos consideraban peor que la muerte y cualquier desgracia. En 1571, por ejemplo, Felipe II se dirigía en los siguientes términos a los alcaldes de Sevilla para reclamarles el servicio de estos hombres:

«El Rey. Nuestros alcaldes de la quadra de la ciudad de Sevilla. Ya sabeis como por nuestra carta de veinte e quatro de enero deste presente año mandamos escrivir que porque haviamos mandado que las quatro galeras que estavan en el puerto de Santa Maria se aprestasen y pusiesen en horden e tenian mucha falta de forzados enbiasedes a ellas lo que ouviese en la carcel desta audiencia condenados a galeras segun mas largo en la dicha carta a que nos referimos se contiene. $E$

${ }^{10}$ Las disposiciones respecto a las penas corporales se encuentran recogidas en la Novísima Recopilación de las Leyes de España mandada formar por el Señor Don Carlos IV. Edición facsímil del B.O.E., s. a., 4 vols. (Libro XII, título XL, ley I: Carlos I en Madrid, pragmática de enero de 1530; ley III: Felipe II en pragmática de 1566).

${ }^{11}$ Nueva Recopilación. Libro VIII, Título 24, Ley XI. Novísima Recopilación. Libro XIII, Título XL, Ley VI. 
aora don Juan de Mendoça nuestro capitan general de las galeras de España nos ha hecho relacion que en esa dicha carcel ai muchos condenados a galeras que se podrian enbiar a que otros que tambien estan condenados a galera en primera instancia que por haver apelado o llamarse a la Corona no sigue sus pleitos en grado de apelacion porque saben que no tiene justicia y huelgan de estar en la carcel con esperança que algun dia la quebrantaran y se yran e algunos desta calidad que ha mucho tiempo que estan en la dicha carcel: Suplicandonos que lo susa dicho es de mucho inconveniente para nuestro servicio fuesemos servido mandaron que embiasedes a las dichas galeras todos los qualesquiera condenados a ellas en la dicha carcel y que a los que estan en grado de apelacion y se ouvieren llamado o llamaren a la Corona les mandasedes que dentro de seis meses acaban sus causas y que no lo haziendo asi los entregasedes en dichas galeras como mandamos que se hiziese en la ciudad de Malaga, o como la nuestra merced fuese. E porque por la necesidad que ai de que las dichas galeras se armen e pongan en orden lo havemos tenido por bien. $\mathrm{E}$ os mandamos proveais que se envien a las dichas quatro galeras todos los que ouviere condenados para ellas en la dicha carcel como os lo tenemos escripto. E que todos los que en ella condenados a servicio de galera que sus causas estubieren en grado de apelacion o que se aian llamado o llamaren a la Corona que dentro de seis meses desde el dia que ouvieren en apelacion no estubieren señalados en revista o dados por libres, los entregueis en las nuestras galeras para donde fuesen condenados sin embargo de las tales apelaciones. Fecha en Toledo a [blanco] de março de mil e quinientos y setenta e un años » ${ }^{12}$.

Según vemos, el rey apremiaba a los alcaldes para que los condenados fuesen a cumplir su servicio en las galeras con la mayor brevedad posible, de acuerdo con la gran demanda que el país tenía en aquel momento de brazos que le defendieran en el mar. La situación se repite periódicamente durante el reinado de Felipe II, y entre los años 1572 y 1575 se ordena una medida similar, destinada en esta ocasión a todas las justicias del reino. Es decir, se intentó llevar a cabo una leva general de hombres destinados al remo. En esta ocasión, los alcaldes, corregidores y demás justicias del reino enviaron sus testimonios acerca del número de condenados a galeras que había en sus calabozos, lo que nos permite disponer de noticias concretas acerca del número de gitanos que quedaron comprendidos en la medida y que cayeron en las redes de la justicia al mismo tiempo que otros infelices similares.

Si tomamos en cuenta las noticias anteriores, aunque los gitanos se encontraron entre los primeros que fueron destinados a cumplir sus condenas en las duras condiciones de galeotes, se trataba de una medida que pronto se generalizó para comprender por igual a todos los habitantes del país cuyos delitos parecieron a los monarcas suficientemente graves como para merecer este castigo. Si tomamos en cuenta el corto, pero sustancioso, estudio de Thompson ${ }^{13}, 158$ personas de esta etnia se encuentran incorporadas entre 1586 y 1589 a las galeras reales, lo que representa un $2,9 \%$ del total. Un $75 \%$ de estos gitanos procedían de Castilla,

12 Archivo General de Simancas (AGS). Guerra Antigua, leg. 70, n. ${ }^{\circ} 373$.

13 I. A. A. Thompson, «A map of Crime in Sixteenth Century Spain», Economic History Review, n. ${ }^{\circ} 21$ (1968), pp. 244-267. 
y sólo el $18 \%$ habían sido presos por los alcaldes de Aragón, Granada y Valencia. Desde mi punto de vista, estas diferencias geográficas pueden ser consideradas ya desde estas fechas como una característica de las diferentes circunstancias que pueden apreciarse en el seno de la minoría.

A pesar de esta necesidad de mano de obra barata, y de la eficacia con que hemos visto aplicar a las justicias las órdenes recibidas en tiempos de Felipe II, las dificultades administrativas y burocráricas propias de la época determinaron con cierta frecuencia que estos hombres quedaran hacinados en las cárceles sin que se terminara de tomar una decisión respecto a ellos. Evidentemente, estas circunstancias aumentaban sus sufrimientos y determinaban que la decisión de la Corona, además de cruel, resultara ineficaz. El alcalde de Málaga se lamentaba de una situación similar en 1581:

«La carcel de esta ciudad esta tan llena de forçados que han acudido de todas partes que ya no caben porque son más de 200 y cada dia ban llegando y no ay prisiones con que tenellos, y an intentado de romper la cárcel para huyrse. Una noche les halle començado un agujero en una pared que si se tardara en llegar una ora mas se escaparan porque la carcel en que estan es muy ruyn y de mal edificio de tapia. Suplica al rey envie algun navio para tomarlos ${ }^{14}$.

Los condenados, como es lógico, no aceptaban mansamente su triste situación, y hacían todo lo posible para librarse de ella, cumpliendo, por otra parte, con la obligación de todo hombre privado de libertad de intentar recuperarla. Aunque los datos a este respecto no son tan abundantes como los hechos que acabamos de revisar, de vez en cuando resulta posible recoger alguna escena de protesta como la que se describe en la siguiente carta de 1545:

«Haviendo suplicado a V. A. a los días pasados ciertas egipcianas fuera servido mandar soltar los egicianos que estavan presos en la Galizabra San Ginés de que es tenedor el capitán Martín de Pedrola. V. M. dió la cédula para que el dicho capitán havida informaçión de que los susodichos eran sus maridos los diese libertad con que dentro de IX dias se abecindasen en cualquier parte destos rreinos y no los cumpliendo y tomándolos fuesen bueltos a servir en la dicha Galizabra y quando dicha cédula se notificó al dicho capitán, los egicianos havian hecho el delito siguiente. Lo qual paresce ser así por información de siete testigos que presenta el dicho capitán. Y es que estando la dicha Galizabra surta en el Puerto de la Villa de Santa Maria del puerto a XIII del pasado mes de mayo, doscientos soldados que en ella avia con el aguazil se despidieron. Y saliendo aquel dia el dicho capitan a buscar otros a la dicha villa y dexando a la guarda de la Galizabra tres soldados, estando cenando a las IIII horas de la tarde entre los XIIII egipcianos se rebolvio cierto ruido maliciosamente y yendo los dichos soldados a poner paz y al primero pusieron una cuerda corrediça al pescueço y a los otros dos maltrataron como llegaron a ellos sin armas. Y una muger que en la dicha Galizabra estaba, con un cuchillo corto la cuerda del dicho soldado y él y ella a tres de los dichos egipcianos haciendo que cesase la questión maliciosa, durante la qual dos ladrones que con

${ }^{14}$ AGS. Guerra Antigua, leg. 70, n. ${ }^{\circ} 373$. 
ellos andavan al remo se desferraron y lo mesmo ocho de los dichos egipcianos y ante lo qual la dicha muger y el soldado se pusiesen al paso de la escala los VII dellos y un ladrón estaban ya en un batel y dando largo pensando alcançarle el otro le dió por temor que no fuesen maltratados se hecho a nadar y se ahogó. E dize que fue el primero se desferró. Y así mesmo se echó a nadar otro gitano que no pudo alcançar la barca y fue luego tomado saliendo a tierra. $Y$ el dicho capitán sabido este subceso dió aviso a los lugares comarcanos y que fuesen tras ellos y los hizieron con toda diligencia pero no an sido tomados asta agora. Que V. Alt. provea en esto y en el soltar a los que quedan tres dellos heridos lo que sea servido pues que tal desacato cometieron ${ }^{15}$ ».

De acuerdo con el documento que acabamos de ver, los galeotes (y los gitanos entre ellos) podían recibir medidas de gracia que adelantasen su libertad, aunque tal vez, como en el caso anterior, llegaran cuando la desesperación les había empujado demasiado lejos. La situación de las cárceles inquisitoriales, a pesar de las opiniones de algunos autores, tampoco era demasiado buena. Las noticias de que disponemos a este respecto son escasas, pero todo parece indicar que en muchas ocasiones resultaba preferible cumplir el tiempo de galeras que se estipulaba en las condenas antes que permanecer en la cárcel tanto real como inquisitorial. Por lo que se refiere a este aspecto, casi todos los documentos señalan que los presos pasaban hambre y dificultades materiales que aliviaban obteniendo permiso para mendigar por las calles o para vender mercancías a un costo inferior al de los establecimientos oficiales, lo que originaba recelos y litigios ${ }^{16}$. El hacinamiento y el hambre, según podremos observar más adelante, causaban a veces más muertes que cumplir el servicio forzado del remo.

Afortunadamente, las circunstancias no fueron siempre tan adversas. De acuerdo con nuestras noticias, al menos en una ocasión durante el reinado de Felipe II la clemencia del rey pudo beneficiar a los condenados. Según una cédula de 25 de febrero y 11 de agosto de $1573^{17}$, se volvió a escribir a las justicias para que se enviaran a todos los gitanos útiles para el remo a las reales galeras. Un año después, el rey escribió al marqués de Santa Cruz para pedirle la relación de los que todavía seguían cumpliendo esta pena. Los gitanos detenidos preocupaban al monarca, y con este motivo se intercambiaron notas entre el rey y el marqués de Santa Cruz que son una buena prueba del escrupuloso cuidado con que Felipe II actuaba en todo aquello que se refería a las cuestiones públicas. En la nota que se ha conservado respecto a este asunto, pueden leerse los detalles acerca de estos hombres:

«[...] quando el Sr. D. Juan [de Austria] fue la primera vez a Levante como abía falta de gente en las galeras para el remo, se acordó se llevase a ellos todos los gi-

${ }^{15}$ AGS. Guerra Antigua, leg. 58, n. ${ }^{\circ} 10$.

${ }^{16}$ Sobre la situación de los presos en las cárceles del Santo Oficio puede verse mi artículo «La situación de los presos en las cárceles del Santo Oficio de Granada», Espacio, Tiempo y Forma, n. ${ }^{\circ} 4$ (1989), pp. 669-684.

${ }_{17}$ AGS. Guerra Antigua, leg. 88, n. ${ }^{\circ} 359$. 
tanos que anduvieran bagando por el reyno y así se hizo. Y por su parte se a pedido que pues se echaron sin culpa y que otros que andan en ella an cumplido las condenaciones que fueron condenados, se les mandase dar libertad y para entender lo que son y las causas porque se hecharon y si los condenados an cumplido se acordó se embiase esta relación para que vista se proveyese lo que conbenga» ${ }^{18}$.

Los propios gitanos, por tanto, se habían dirigido a Felipe II para pedir su libertad, y es también el monarca quien se ocupa del caso, al parecer, a pesar de los graves momentos por los que atravesaba la Corona. El marqués de Santa Cruz comunicó que en las galeras había 59 gitanos, 27 de los cuales estaban condenados a seis años al remo desde el mes de abril de $1573^{19}$. Es decir, años antes de que tuviese lugar este cruce de noticias. Los restantes habían sido entregados sin que se especificara el tiempo que habían de cumplir, puesto que se les apresó de acuerdo con las cédulas mencionadas.

El rey concedió la libertad a estos gitanos, aunque en el documento se especifica al margen que se les volverá a enviar a galeras si reinciden en sus delitos ${ }^{20}$.

El reinado de Felipe II fue, según vamos viendo, el periodo durante el cual la Corona tuvo más necesidad de reclutar hombres para el mar, especialmente para las empresas de don Juan de Austria, pero no terminan con este monarca las tribulaciones de los gitanos y restantes reos que cumplieron penas de galeras, puesto que también a lo largo del siglo XVII menudean las noticias a este respecto.

Por lo menos en cuatro ocasiones ${ }^{21}$, Felipe IV recurrió también a las mismas medidas que su abuelo para reunir galeotes, aunque no siempre las disposiciones que se dictaron al respecto sirvieron para reunir el número de brazos que requería el servicio de la guerra. Así, por una parte, Felipe IV dicta el 13 de octubre de 1638 nuevas disposiciones que pretenden impedir los indultos y excepciones, renovando la prohibición. Por otra, y de acuerdo con la real cédula de diciembre de $1638^{22}$ se disponía que don Pedro de Amezquita sería el hombre adecuado para ocuparse del problema. En la práctica no parece, sin embargo, que la actuación de los monarcas o de las justicias fuera siempre tan severa como hace suponer este decreto.

En junio de $1637^{23}$ tenemos noticias de las dificultades que experimentaba Pedro de Amezquita, después de un decreto del propio rey que había indultado a muchos de estos infelices, para reclutar los galeotes necesarios para los navíos reales, a causa de las apelaciones e indultos y retrasos que impedían reunir los

\footnotetext{
18 Ibidem.

19 Ibidem.

${ }^{20}$ Ibidem.

${ }_{21}$ A. Domínguez Ortiz alude a estas leyes en su breve pero inestimable trabajo La esclavitud en Castilla durante la Edad Moderna, Madrid, CSIC, 1952.

22 Archivo Histórico Nacional (AHN). Consejos, leg. 7155.

23 Ibidem.
} 
condenados que convenía destinar a este servicio. La deliberación del Consejo de Castilla a este respecto demuestra el estado de confusión a que daban lugar las apelaciones, y la diversidad de las medidas jurídicas conducentes a la leva de galeotes:

«En el Consejo se ha visto un decreto de V. Magestad del tenor siguiente: Haviendome consultado el Consejo de guerra que el alcalde Amezquita habia avissado por allí que en Toledo havia muy pocos galeotes por no haver llegado las cadenas de Valladolid y Soria y que en los demas lugares no havia hallado ninguno, porque los del donatibo los indultaban y que las causas de algunos sentenciados por las justicias ordinarias en primera instancia estavan en apelación en Granada y que de los rematados en Sevilla havia soltado don Gaspar de Bracamonte veinte. He yo atendido a lo mucho que importa proveer de forçados a las galeras he resuelto de mandar que se execute lo que tengo ordenado precissa e indispensablemente, y ordenareis a los que indultaron que buelvan a poner de manifiesto a los dichos forçados y assi se lo escrivireis luego y que las apelaciones de las justicias ordinarias es mi voluntaad que se remitan al alcalde para atajar las dilaciones que ay en las Chancillerias en la deteminación destas causas en lo qual dareis tambien las ordenes convenientes luego ${ }^{24}$.

El Consejo estima, en vista de la falta de hombres para este trabajo, que es preciso actuar con prudencia por lo que se refiere a los indultos y dispone que se comunique a todos los que han intervenido en el decreto de las apelaciones e indultos de forzados «cumplan con satisfacción entera lo que V. Majestad ha sido servido de mandar en lo que toca a los forçados rematados que huvieren indultado en conformidad del real decreto, que en los que no lo estavan sino condenados solamente por las justicias ordinarias sujeta su condenación a rebocarse en los tribunales y audiençias a quien pertenesce su conocimiento en apelación o por ellos en vista no milita la misma raçon pues puede haver mobido la poca justificación dela causa al que le indultó, que para este efecto la ven antes, junto con acudir al servicio de $\mathrm{V}$. Magestad con cantidad de maravedis proporcionada al casso a que le concediesen, que no corre igualmente en los rematados por V. Magestad se lo manda se execute su real decreto como se hace ${ }^{25}$. De acuerdo con la urgencia de la situación, se determina que en adelante se remitan estas causas al alcalde D. Pedro de Amezquita «para que conozca dellas, por hallar el Consejo conocidos reparos e inconbenientes le parece de su obligación representarlos a V. Magestad para que destos mande lo que mas fuere servido ${ }^{26}$. El Consejo sigue deliberando acerca de lo que resulta conveniente respecto a las causas civiles y criminales "que tocan a la honra», respecto a las que recomienda ${ }^{27} y$ termina aconsejando que las causas se despachen con la mayor brevedad posible.

Al parecer las dificultades para reunir galeotes eran tan grandes que Amezquita había recibido también la orden de reclutar esta mano de obra entre los esclavos

\footnotetext{
24 Ibidem

${ }_{25}$ Ibidem.

26 Ibidem.

${ }_{27}$ Ibidem.
} 
de Andalucía, donde eran particularmente abundantes como servidores domésti$\cos ^{23}$. El 25 de agosto de $1637^{29}$ el Consejo volvía a informar sobre los obstáculos que presentaba una misión que perjudicaba especialmente a las familias propietarias de estos hombres que, indudablemente, no estaban acostumbrados a trabajos tan duros. Según el memorial que recibió el Consejo, la mayor parte de ellos, especialmente los cristianos, «trabajaban para sustentar a sus amos, muchos de los cuales eran pobres, viudas, o personas principales y honrradas que no tienen otra cossa de que vivir sino lo que por medio de ellos adquieren y negocian cossa muy ussada en aquesta tierra y que si no ubiesse en ella esta gente que acudiesse a estos ministerios y que sirbiesse no ay otra que lo pueda hazer». Los propios miembros del Consejo se sienten inclinados a pedir clemencia al rey para amos y esclavos. Para los esclavos, porque están presos y hacinados, y la situación es tan grave que se teme que pueda dar lugar a algún contagio. En el caso de los amos, porque «andan llorando publicamente por las calles llebados del dolor de verse sin sus esclavos en que consistía parte de su hazienda y en algunos toda, el sustento de sus familias y casa». La situación de los detenidos, por otra parte, inclina al Consejo a consideraciones relacionadas con su fe cristiana que aconsejan también su libertad: «y que juntamente se teme que en los esclavos como gente de tan pocas obligaciones con la inpaciencia de berse llebar a galeras sin delito suyo se abenture la fee que es en lo que mas debe repararse». Las dificultades de Felipe IV para reunir galeotes le obligan a comisionar de nuevo en diciembre de 1638 a Pedro de Amezquita ${ }^{30}$ para que se ocupe del asunto mediante un decreto en el que se observan las mismas complicaciones de carácter jurídico que en el caso anterior:

«El Consejo tiene entendido el cuidado y solicitud con que procuran por todos los medios que son posibles a acrecentar galeotes de las galeras y la importancia del efecto desto, supuesto lo qual, por havese entendido que ay en las Chancillerias muchos pleitos pendientes de sentenciados a galeras, he resuelto que por el Consejo se escriva a los governadores de las Audiencias de Valladolid y Granada y Regente de Sevilla que dentro de cinquenta dias se vean que sentencian en todas instancias los pleitos de los que están conducidos a galeras, o lo pueden ser, no perdiendo ora de tiempo aunque sean vacaciones y que cada ocho dias os den aviso a vos el Arzobispo Governador de los pleitos que se sentenciaren y galeotes de que dello resultaren, los quales entregareis al Secretario de la Junta, donde se tratará de materias de los galeotes. Asimismo, he resuelto que salgan personas de satisfacción por el reino y reconozcan los pleitos de los que estuvieren sentenciados en vista de galeras y determinen si se pueden executar las sentencias sin embargo de apelación y en las que se pudieren hacerlas executar y las que no las remitiran a las Chancillerías para que las causas se fenezcan y las condenaciones de muerte en que no aya parte las puedan conmutar en galeras y quitar los azotes y verguença dejando las condenaciones de galeras y que sin embargo las partes puedan seguir sus apelaciones aunque sean entregados a las galeras y se guarde lo que por la ultima sentencia se determinare»31.

\footnotetext{
¿s A. Domínguez Ortiz, La esclavitud...

29 AHN. Consejos, leg. 7155.

30 Ibidem.

31 Ibidem.
} 
En 1640 todavía se continuaban dictando órdenes para conseguir reunir galeotes, lo que viene a confirmar la necesidad de esta mano de obra, y las dificultades con que se tropezaba a la hora de hacer cumplir las medidas:

«14 de marzo de 1640. He entendido que aunque en ejecución de lo que tengo mandado al Consejo se curan por el órdenes muy apretadas para que todos los sentenciados a galeras se revistan así en esta corte y villa como en Valladolid, Granada y Sevilla, se llevasen luego a las cajas para conducirlos con los demás galeotes al Puerto y que se avisase de todas las partes a mediado este mes de marzo los que uviese licenciado y que estado tiene la conducción; no camina esto con la celeridad que insta la necesidad que hay de chusma para las galeras y assi he resuelto que de nuevo se envien más apretadas órdenes a los gobernadores de las dichas Chancillerias y Regente de Sevilla para que ejecuten lo que está ordenado con suma brevedad, y lo mismo se haga en esta Corte y villa, de manera que para fin de este mes estén en Cartagena todos los galeotes de las cajas de sus distritos y vandos en cavalgaduras y culparlos al no haber respondido lo que en esto se les ha ordenado. También ordenareis al Corregidor de Toledo que parta la cadena de allí luego pues ha avisado que hay 37 galeotes rematados y porque los comisarios que salieron por el sy a lo tocante a galeotes no han cumplido con la orden de enviar relación cada 4 dias ${ }^{32}$.

El 30 de marzo de $1640^{33}$ se reiteraban las órdenes solicitando que los comisarios y oidores enviaran a los condenados a la costa con la mayor brevedad posible sin que tengamos noticias exactas de cuántos galeotes fueron recogidos en total, y cuántos gitanos había entre ellos. De acuerdo con una carta de 16 de marzo de $1640^{34}$, en las cárceles de Toledo había 40 forzados que esperaban a ser enviados sin que hubiera dinero para hacerlo, ni suficientes prisiones para retenerlos. Parece evidente que las órdenes para reunir forzados tropezaban en la práctica con grandes dificultades que conducían periódicamente a recordar a las justicias la necesidad que se tenía de esta gente, a pesar de lo cual en cada caso sólo se conseguía reclutar a un número de personas bastante reducido. El 2 de marzo de 1645 se apremia de nuevo a las justicias en términos muy similares a los que acabamos de ver ${ }^{35}$.

Según puede deducirse de la abundante correspondencia que acabo de citar, la España de los siglos XVI y XVII recurrió con frecuencia a los servicios de los condenados a galeras, entre los que se encontraba casi siempre un porcentaje de gitanos $^{36}$. En las mencionadas órdenes de 1645 volvemos a encontrar una alusión concreta a los gitanos «vagantes» que quedan comprendidos en la medida:

32 Ibidem.

33 Ibidem.

34 Ibidem.

35 Ibidem.

${ }^{36}$ El porcentaje podía ser mínimo, pero el número de gitanos condenados a galeras debe situarse siempre, como es obvio, en el contexto de la propia población gitana, cuyo contingente no era superior por esta fecha a dos mil o tres mil almas aproximadamente. Es decir, una minoría sumamente reducida. 
«[...] que disponga que se lleven a las galeras todos los xitanos que anduvieran vagando según está dispuesto en las leyes y que respecto de que Alberto Pardo ha ofrecido correr en su conducción le ordena lo ejecuten con mucho aprieto» ${ }^{37}$.

Los gitanos, por tanto, padecieron en teoría y de acuerdo con las leyes específicas que se elaboraron contra ellos el servicio de las galeras reales a las que fueron a parar en tanto que condenados por la justicia real o en cumplimiento de las pragmáticas reales que disponían esta pena para todos aquellos que fueran encontrados vagando por el reino, situación de la que aparecen noticias esporádicas a lo largo de los siglos XVI y XVII. Todavía a principios del siglo XVIII tenemos de nuevo noticias de tres gitanos que se habían refugiado en sagrado para no tener que cumplir esta terrible condena y que fueron sacados del lugar donde se habían refugiado para ser entregados de nuevo a la justicia. El asunto, sin embargo, fue considerado de forma minuciosa y nos permite entender con claridad los criterios del Consejo acerca de este tipo de cuestiones. La Junta de Abastos de Galeras remitió al Consejo una consulta acerca de estos gitanos, que estaban sirviendo, al parecer, en la ciudad de Málaga:

«Por la consulta de la Junta del apresto de galeras y papeles que la acompañan parece que en virtud de letras requisitorias del Juez ordinario eclesiástico de Ziudad Real y Campo de Calatraba ha embargado y retenido en la carcel real de Malaga el Probisor de aquel obispado las personas de Agustin de Montoya, Francisco de Heredia y Alvaro de Heredia, gitanos rematados a ziertos años de galeras por decir que en el año pasado de 1691 se les sacó de la hermita de la Magdalena de la viIla de Daimiel por la Justicia real y que, aunque fueron sueltos, no se les restituio a la Iglesia de que resulta estar vulnerada la inmunidad y respecto de que la defensa de la jurisdicción real, que es la principalmente interesada, toca al tribunal donde se entendió la causa de estos gitanos, se da órden por el Consejo al fiscal del Crimen de la real Chancillería de Granada conteste con el Juez eclesiástico esta competencia en la forma ordinaria y será combeniente que V. M. mande por donde toca, al Probeedor General de Armadas y fronteras de Malaga subministre al fiscal del Crimen los Autos y recados necesarios para la defensa de la jurisdicción real. Con este motibo no escusa el Consejo de representar a V. M. el grave perjuicio que se sigue a la administración de la Justicia de que en las hermitas sitas extra muros de las poblaciones se goze del refugio de la Inmunidad y de que persebere este asilo en el refugiado siempre que por las Justicias Reales se les saca de la iglesia o hermita y aunque sea suelto no consta de su restituicón a ella porque como la piedad y la devoción christiana tiene para sus rogatibas y espirituales ejercicios repetidas hermitas distantes algo de las poblaciones sirven esta a la gente de mal bivir, y en especial a los gitanos de rezeptáculo donde se aseguran... ${ }^{38}$.

El Consejo termina su largo informe rogando al rey se ordene devolver estos hombres a sus trabajos forzados, y se hagan gestiones cerca de la Santa Sede para impedir este tipo de situaciones. La medida, indudablemente, era una de las penas más graves a las que se podía condenar a un reo, llegando incluso a susti-

${ }^{37}$ AHN. Consejos, leg. 7155.

38 Ibidem. 
tuir por ella la pena de muerte, según hemos visto. Los textos literarios que dan fe de las características y sufrimientos de los galeotes constituyen ya casi un tópico, lo cual no es óbice para que arrojen luz sobre determinados aspectos, como el del carácter de estos individuos a los que la justicia enviaba a este duro trabajo con cierta frecuencia por delitos no demasiado importantes.

De este modo, Cervantes describe con pena y cierta socarronería la «hazaña» que lleva a cabo Don Quijote al liberar a un grupo de forzados con quienes se tropieza y cuya descripción resume perfectamente las características de estos hombres, a juzgar por los documentos que vamos viendo, al tiempo que nos permite contemplar desde la perspectiva literaria el mismo panorama humano a que hemos pasado revista en estas páginas. Así, en el abanico de caracteres dibujado por la pluma cervantina aparece un condenado porque se había «enamorado» de una canasta repleta de ropa blanca, algo bastante costoso en aquella época. Otro es un mozo de unos 24 años natural de Piedrahita, condenado por un «canario», es decir, después de haber «cantado» en el tormento confesando que era ladrón de bestias. El tercero explica que no pudo sobornar al escribano con diez ducados que había robado. El cuarto, un anciano de «venerable rostro» que aparece en el grupo y rompe a llorar ante las preguntas de Don Quijote, ha sido condenado a través de la Inquisición por sus actividades como alcahuete y hechicero. El quinto, al parecer un estudiante («mozo grande estudiante y muy gentil latino»), desfiló ante los tribunales por estupro en la persona de casi todas sus primas. Finalmente, el sexto galeote descrito por Cervantes es el «famoso» bandolero o ladrón de caminos Ginés de Bracamonte, quien ya había cumplido condena en galeras con anterioridad durante cuatro años. Un grupo, pues, a caballo entre la picaresca y la delincuencia. No es extraño, por tanto, que los galeotes aparezcan también con cierta frecuencia en este género literario ${ }^{39}$.

39 El fragmento literario es el encuentro entre Don Quijote y una cuerda de condenados a galeras, que merece la pena recordar puesto que refleja a la perfección el triste destino de estos desgraciados, merecedores de una empresa caballeresca:

«Don Quijote alzó los ojos y vió que por el camino que llevaban venían hasta doce hombres a pie, ensartados como cuentas en una gran cadena de hierro, por los codos, y todos con esposas a las manos. Venían asimismo con ellos dos hombres de a caballo y dos de a pie, los de a caballo con escopetas de rueda, y los de a pie, con dardos y espadas; y que así como Sancho Panza los vido, dijo: >Esta es cadena de galeras, gente forzada del rey que va a galeras.

$>$ ¿Cómo gente forzada?, preguntó Don Quijote-¿Es posible que el rey haga fuerza a ninguna gente?

$>$ No digo esto -respondió Sancho- sino que es gente que por sus delitos va condenada a servir al rey en las galeras, de por fuerza.

>En resolución -replicó Don Quijote- como quiera que ello sea, esta gente, aunque los llevan, van de por fuerza y no de su voluntad.

$>$ Así es -dijo Sancho.

>Pues desa manera -dijo su amo- aquí encaja la ejecución de mi oficio: desfacer fuerzas y socorrer y acudir a los miserables.

>Advierta vuestra merced -dijo Sancho- que la justicia, que es el mesmo rey, no hace fuerza ni agravio a semejante gente sino que los castiga en pena de sus delitos.»

(Miguel de Cervantes Saavedra: Primera parte del ingenioso hidalgo Don Quijote de la Mancha, cap. XXII. Edición, introducción y notas de Martín de Riquer, Barcelona, RBA, 1994). 
El servicio que esperaba a estos desgraciados era duro y penoso. A ello se alude en un texto citado por Félix Solanas Sevilla:
«Casa angosta y poco alta
Casa para padescer
do riguridad de esmalte.
Casa es don nunca falta
De contino qué hacer» ${ }^{40}$.

Sin embargo, mejor que a través de cualquier testimonio literario, llegan los lamentos de estos infelices a través de los memoriales presentados por los propios interesados tanto al tribunal del Santo Oficio como a los representantes de la justicia real. En julio de 1607 dirigía Domingo López el siguiente memorial a los inquisidores en un intento desesperado por conseguir su libertad:

«Domingo López portugués penitenciado por tres años de galeras por los señores inquisidores de esta ciudad del Santo Oficio preso en la carzel pública de esta ciudad de Cordova digo a vuestras señorías que yo aqui estoi preso en esta dicha carcel beinteiseis meses sin aver orden de llevarme a cunplir mi sentencia estoi enfermo padeciendo muchas necesidades desnudo y descalço sin remedio sino de dios cargado de jierro y con mil trabaxos.

Pido y suplico a vuestras señorias como misericordiosos que son pues soi honbre maior de edad de cinquenta años antes mas si que no menos y con mi muxer la primera muerta y con tres hijas donçellas sin remedio una de diez y siete años y otra de treze y la otra de seis años que esto que e estado preso se me desquente de mi penitencia o trabaxo a servir en concierto o espital porque como soi viejo como tengo dicho estoi sin vigor de poder llevar tanto trabaxo con el servir en galera haran vuestras señorias servicio a dios y a mi caridad para que yo pueda remediar mis hijas» ${ }^{41}$.

La actitud de los inquisidores no fue siempre, sin embargo, totalmente implacable. En 1740 exponía su caso Matías Montoya, quien había sido condenado a galeras. Explicaba que se encontraba enfermo del pecho, por lo que solicitaba se le conmutara esta pena. Depués de someter el caso a la revisión de un médico, los inquisidores dispusieron que no había inconveniente en sustituir este castigo por el de diez años de destierro ${ }^{42}$. En noviembre de 1682 tenemos noticias de dos gitanos que se dirigieron al rey para suplicarle que conmutara sus penas de galeras por la del trabajo forzado en las minas de Almadén ${ }^{43}$. Sebastián y Manuel Abendaño eran naturales de Aranda de Duero y estaban presos en la cárcel de Palencia, desde donde enviaron un memorial en noviembre de 1681 solicitando la conmutación de su pena. En el memorial referían que habían sido condenados a seis años de galeras a causa del proceso que formó contra ellos el corregidor de Palencia en la

\footnotetext{
40 F. Solanas Sevilla: Historia...

${ }^{41}$ AHN Inquisición, leg. 2679.

42 Ibidem.

43 Ibidem.
} 
Chancillería de Valladolid por decir que eran gitanos y hablar la lengua jerigonza. Suplicaban que se les diese permiso para cumplir la condena en las minas de Almadén, donde, por lo menos, no se verían privados del consuelo de sus mujeres e hijos, y del socorro que ellos les pudieran dar. Afortunadamente para nuestros condenados, el Consejo estimó que se les podía conceder la merced. En este caso, nuestros gitanos pudieron escapar de esta horrible pena.

Al margen de estos casos más o menos aislados, la suerte de los condenados a galeras era seguramente la peor del país, según parece desprenderse también de la siguiente carta a propósito de los detenidos con el mismo destino por el Santo Oficio:

«Nosotros, Bartolomé Moriana, Francisco Hidalgo, Juán Diulloca y los demas presos por la santa Inquisición, hablando con el devido respeto que se requiere decimos que aciendo seis meses que estamos aquí en esta cárzel pública padeciendo muchas y graves necesidades, así de vestidos como de [blanco] que para estar en este mundo de lo qual nos querellamos ante Dios Nuestro Señor y ante vuestras señorías.

Pedimos y suplicamos a vuestras señorías que se nos dé algún remedio para salir de aquí de este ynfierno para pagar nuestras culpas pues a tanto tiempo que padecemos tantos trabaxos según arriba ba referido que en ello harán vuestras señorías servicio a dios y a nosotros caridad y limosna» ${ }^{44}$.

Los presos que firmaban este escrito en la cárcel pública el año 1607 llevaban tanto tiempo esperando a que se les enviara a cumplir sus condenas que según un testimonio del propio tribunal muchos habían muerto ya a causa de sus necesidades en la prisión, y los propios funcionarios señalaron a la Suprema que sería mejor enviarles a las galeras antes que mantenerlos en la cárcel soportando los sufrimientos a que estaban sujetos. Estas noticias parecen confirmar los datos a que aludí anteriormente acerca de los terribles padecimientos de los condenados que permanecían en la cárcel esperando su juicio o el destino decidido en la sentencia.

Entre los condenados que firmaban este escrito en Córdoba no había ningún gitano, puesto que pocas veces cayeron en manos de los inquisidores por delitos que pudieran merecer esta pena, pero ya hemos visto con cuanta frecuencia, sin embargo, fueron comprendidos en las medidas que se dictaron con este motivo durante los siglos XVI y XVII.

Los sufrimientos de los galeotes, en cualquier caso, parece que fueron tan temidos como la propia pena de muerte. El 5 de enero de 1647 Francisco Martínez de Mata - «siervo de los pobres afligidos»-conseguía mediante la presentación de un memorial al rey que se les devolviese la libertad a un grupo de forzados que ya habían cumplido su servicio en las galeras reales. Los términos en que se ex-

44 Ibidem. 
presa este hombre entregado al ejercicio de la caridad con los penados, sitúan mejor al lector que cualquier testimonio literario ante las penalidades de los miles de desgraciados que fueron a dar con sus huesos en las cárceles del Antiguo Régimen y «mejoraron» a continuación su suerte contribuyendo con su esfuerzo a las empresas bélicas del país:

«Señor: Francisco Martínez de Mata, natural de Motril, siervo de los Pobres afligidos, Digo, que por merced que dios me ha hecho, tango vocasión y exercicio de acudir a el consuelo y remedio de Pobres de Cárcel y Forçados de Galeras, y en ellas, he visto cosas tan lastimosas, que me han obligado a venir a mi costa, a representarlas a v. Magestad, y pedir su remedio. Y es Señor, que no se cumple lo que vuestra Magestad manda, en las sentencias de sus Juezes: porque entrando los Forçados, por limitado tiempo, no se les da la soltura en cumpliendo y aunque, antes ay muchos que despues de aver cumplido, passan muy largo tiempo, como son 2, 4, 6, 8 años y de alguno tuve noticia, avia dies años que avia cumplido y aunque estos piden su libertad, como de justicia se les deve, no son oydos sus clamores, de que resultan gravísimos daños, como son las blasfemias y maldiciones que contra sí mesmos y contra quien assi los detiene, pronuncian desesperadamente, y las enfermedades, y assidentes de muerte en que muchos causa el verse tan agraviados de los mesmos Christianos que professan Ley que no permite agravios y no sólo en estos que han cumplido y se ven detenidos, haze suerte la desesperación, sino en los que de nuevo entran porque viendo este agravio, que passa en común le aprehenden sin remedio, y desesperan de su libertad, y aumentada esta pena la de su castigo, causa en muchos enfermedades de muerte, que ay algunos que no quieren recevir los Sacramentos ni aun para morir, cosa que por evitarla, se mando por decreto de vuesta Magestad, que ningun Forçado se le diese mas de diez años de Galeras, esto Señor, demás que consume muchos Forçados que mueren con riesgo de sus almas, es en perjuyzio y descredito de los Ministros superiores, que deven mantenernos en justicia; y pues a ninguno puede negarsele la justicia que tiene, no sean ellos Pobres danificados, valgales el aver cumplido sus penitencias, y no permita V. Magestad que la defensa de la Fe sea a fuerza de agravios, pues cierto no se dará a Dios por servido, ni ayudará con buenos sucessos... ${ }^{45}$.

Si tenemos en cuenta que los reos destinados a este castigo tenían el variado origen que ya vimos (moriscos, esclavos, etc.) no resulta aventurado señalar que el porcentaje de los gitanos que contribuyeron a engrosar este grupo de desgraciados fue bastante escaso. Por lo que se refiere a las galeras del Santo Oficio, sólo gitanos aparecen condenados a este terrible destino ${ }^{46}$. Las referencias respecto a los que fueron enviados a galeras por las justicias reales son esporádicas y, si exceptuamos el pequeño contingente de individuos de esta etnia que sirvió en las galeras de don Juan de Austria, el resto de los casos sólo hablan de tres o cuatro gi-

45 Biblioteca Nacional. Raros. Cf. la edición de los Memoriales y Discursos (1650) de MARTínEZ DE MATA, debida a G. ANES, Madrid, Moneda y Crédito, 1971.

${ }^{46}$ M. H. SÁNCHEZ ORTEGA, La Inquisición y los gitanos, Madrid, Taurus, 1987. Los gitanos condenados a galeras por el Santo Oficio serían los siguientes: Juan Montoya (Valencia, 1690, tres años), Diego Montoya (Valencia, 1690, tres años); Juan de Montoya (Granada, 1688 — ¿el mismo?-, cinco años), Juan Mario (Zaragoza, 1583, cuatro años), Juan Escudero (Zaragoza, 1588, seis años). 
tanos, según hemos visto. Así pues, aunque las penas dictadas contra los gitanos resultan bastante duras desde el punto de vista legislativo, la consulta detallada de la documentación que se ha conservado al respecto parece indicar que, al igual que ocurrió con el decreto a propósito del destierro o la esclavitud, los gitanos consiguieron librarse con bastante frecuencia de tan triste suerte o la padecieron de forma similar a la de los restantes desgraciados que cayeron en las redes de la justicia real o del Santo Oficio. 